\title{
Individuação e psicanálise: pontes entre Freud e Simondon
}

\author{
ÁdAMO BOUÇAS ESCOSSIA DA VEIGA *
}

* Mestre em Filosofia pela PUC-Rio

Boutorando em Filosofia pela PUC-RIO

adamo.veiga1@hotmail.com
RESUMO O presente artigo se pretende uma análise da psicanálise de Sigmund Freud sob a ótica da ontologia da individuação em Gilbert Simondon. O que pretendemos é analisar a convergência do conceito de isso na obra freudiana com o conceito de Pré-Individual na metafísica de Simondon. Exporemos os caracteres principais de ambos os conceitos a fim de precisar tal convergência. Na filosofia de Simondon, o Pré-Individual corresponde à Natureza, entendida como diferença dinâmica contemporânea a qualquer ente individuado. Na psicanálise freudiana, o isso corresponde a instância mais afastada da consciência individual do ego. Mostraremos como propriedades do isso - como a dinâmica das catexias, a ausência de contradição lógica e temporalidade, dentre outras - permitem associá-lo ao Pré-Individual. A partir disso, proporemos que o isso é a própria Natureza. Acreditamos que tal análise se justifica na medida em que oferece uma outra leitura da individuação psíquica dentro do quadro teórico simondoniano.

PALAVRAS-ChAVE Simondon, Freud, individuação, Isso, ontologia.

ABSTRACT The present work intends an analysis of the Freudian psychoanalysis through the optics of the individuation ontology of Gilbert Simondon. What we intend is to think the convergence of the Freudian It. with the with the concept of the PreIndividual in Simondon's metaphysics. In Simondon's philosophy the Pre-Individual corresponds to the Nature, understood as a dynamic difference contemporary to any individual being. In Freudian psychoanalysis the Id corresponds to the most distant instance from the Ego. We shall demonstrate how the properties of the It - as the pulsional dynamics, the absence of logical contradiction and time, along others - allow us to associate it with the Pre-Individual. From this, we shall propose that the It is Nature itself. We believe that such an analysis justifies itself in so far as it offers other possible lecture of the psychic individuation in Simondon's theoretical frame.

KEYWORDS Simondon, Freud, individuation, It, ontology. 


\section{INTRODUÇÃO}

O que pretendemos no presente estudo é uma transdução entre a filosofia da diferença de Gilbert Simondon e a topologia psíquica da psicanálise freudiana. Simondon, com efeito, aplica ele próprio a sua teoria da individuação à ontogênese do psíquico; no entanto, suas referências são voltadas, sobretudo, para as teorias psicológicas norte-americanas, como gestalt e o behaviorismo.

Acreditamos, no entanto, que a psicanálise oferece um campo de aplicação mais interessante à teoria da individuação do que a psicologia. Na filosofia contemporânea, ela se constitui enquanto inspiração e referência teórica para diversos autores, como Deleuze e Guattari, Jacques Derrida, dentre muitos outros. Desde que ela surgiu, na virada do século retrasado, a filosofia não pôde, com efeito, deixar de responder a ela.

Deste modo, pela sua riqueza teórica, optaremos, de forma, talvez, um tanto arriscada, por desenvolver o pensamento da individuação não sob a psicologia, mas sob a psicanálise, focando-nos, sobretudo, no texto freudiano.

Para tal, será necessário operar certos deslocamentos, tanto dos conceitos específicos de Simondon no que concerne à individuação psíquica, como nos de Freud. Tais deslocamentos se veem justificados no próprio pensamento de Simondon, que como coloca Jean Chateau, se pretende uma análise de “como diferentes domínios totalmente separados por princípio, ontológica e metodologicamente, podem ser postos em relação uns com outros dentro do quadro de um novo enciclopedismo."(CHATEAU, 2015, p. 11) Trata-se sempre de pesquisar relações analógicas entre os diversos estratos do ser (físico, vital e psíquico) e os diferentes campos do conhecimento sem que eles sejam reunidos sobre uma totalidade unificante, mas, pelo contrário, sendo dados na sua própria especificidade e diferença. O conceito de transdução opera justamente nisto: colocar em relação às heterogeneidades conceituais de forma a produzir pela sua tensão uma nova individuação teórica. Deste modo, procuraremos estabelecer uma relação deste tipo entre o conceito de isso de Freud e o Pré-Individual de Simondon. 


\section{O PRÉ-INDIVIDUAL}

O pré-individual, em Simondon, se identifica ao próprio ser enquanto natureza. Ele se distingue dos entes individuados ao mesmo tempo que permanece contemporâneo a eles. No processo de individuação temos uma diferença do ser consigo mesmo, uma disparação, tensão de forças, identificado a um estado metaestável - um estado passível de mudança por acréscimo ou decréscimo de energia, em desiquilíbrio dinâmico - repleto de potenciais disponíveis. É um estado fundamentalmente intensivo. Será a partir da solução desta diferença intensiva em um caso de identidade que teremos o indivíduo enquanto estruturação e atualização. O pré-individual corresponde justamente a esta diferença do ser consigo; a sua permanência no indivíduo é o que Simondon denomina “carga de natureza associada." e será aquilo que permitirá que ele passe por uma nova individuação através da solução dos potenciais ainda disponíveis, desta permanência de diferença. (Simondon, 2008).

O pré-individual é o ser completo e, enquanto tal, ele é pura tensão ainda não resolvida, ainda não individuada. Ele é anterior ao indivíduo, pois este será o seu desdobramento enquanto individuação. A individuação é a passagem de fases no ser, e esta passagem corresponde à solução deste desequilíbrio. Esta passagem de fase é a gênese mesma de fases, segundo o qual o ser se tornará polifásico: é o devir do ser enquanto tal: “o devir é o ser que se defasa em relação a si mesmo, passando ao estado do ser sem fase ao estado de ser segundo fases, que são suas fases.” (Ibidem, p. 483)

A oposição entre ser e devir, para ele, é um erro tradicional da metafísica. Para Simondon, o devir é um momento do ser e o ser se mantém no devir. Um pensamento que pretenda dar a ontogênese a ela mesma, como o de Simondon, deve conceder ao devir o devido caráter ontológico. Na medida em que o ser é mudança de fase, que é defasagem em relação a si mesmo, ele é também devir. A ausência do conceito de metaestabilidade não oferecia aos antigos senão a alternativa entre um ser como pura imobilidade ou mobilidade absoluta: Parmênides ou Heráclito. A metaestabilidade nos abre a possibilidade de um ser que é mais do que um, e, simultaneamente, gênese do múltiplo. Escreve Simondon:

Segundo a doutrina que apresentamos, o ser nunca é Uno; quando é monofásico, pré-individual, é mais que uno; é uno porque não pode ser decomposto, porém tem em si mesmo como ser mais do que é em sua atual estrutura; o prin- 
cípio do terceiro excluído só se aplicaria em um ser residual incapaz de devir; o ser é muitos, no sentido de uma pluralidade realizada; o ser é mais rico que a coerência consigo mesmo. (Ibidem, p. 483)

O devir é, assim, um aspecto do ser em uma relação não-hierárquica. O devir é a individuação enquanto aspecto ontológico, dado que ela é consequência desta diferença e do excesso do ser em relação a si mesmo: “o devir não se opõem ao ser; é relação constitutiva do ser enquanto indivíduo" (Ibidem, p. 107). No entanto, é necessário frisar que o pré-individual não é um absoluto, algo fora do mundo de indivíduos. Ele é sempre relativo, pois é a carga de natureza associada aos indivíduos e que os permite novas individuações. Ele é contemporâneo aos entes individuados, e se pode ser pensado em termos absolutos - um pré-individual puro, alheio a toda individuação - é de forma apenas teorética, conceitual.

É necessário frisar que o pré-individual entretém o mesmo tipo de relação com a temporalidade. O passado e o futuro são derivados de um processo de individuação e não são anteriores a ele. Dar a ontogênese a ela mesma deve envolver o tempo no seu modo genético e constituinte. O devir enquanto individuação é presentificação. $\mathrm{O}$ passado e o futuro se dizem a partir da individuação, e não a envolvem de antemão. $O$ pré-individual, a tensão antes da solução, só se torna passado a partir dela: “o devir é o ser como presente na medida em que se defasa atualmente em passado e futuro" (Ibidem, p. 486).Outra característica notável é a ausência de contradição lógica. Esta só pode se dar entre indivíduos e não para além deles; apenas a partir da individuação dos termos que estes podem entrar em contradição. Para Simondon, a relação é ontologicamente anterior aos termos, de tal modo que o problema se torna ontogenético em relação aos casos de solução. Se o pré-individual comporta uma contradição, ela não é entre proposição A e proposição B, mas aquilo que permite a emergência tanto de A quanto de B. (Ibidem)

\section{CARACTERÍSTICAS COMUNS ENTRE O SISTEMA ICS. E O PRÉ-INDIVIDUAL}

De forma resumida, o isso freudiano caracteriza-se "pela isenção de contradição mútua, pelo processo primário (mobilidade das catexias), pela atemporalidade e a substituição da realidade externa pela psíquica.” (FREUD, 1996a, p. 192.) Primeiramente, a isenção de contradição mútua, de negação, significa tanto que o inconsciente não compreende em si mesmo o freio aos seus impulsos pulsionais - freio dado através 
do ego e do superego com seu princípio de realidade - e, igualmente, que ele não reconhece contradições lógicas: "as leis lógicas do pensamento não se aplicam ao Id., e isto é sobretudo verdadeiro quanto a lei da contradição.” (Idem, 1996b, p. 83). Em um sonho, eu posso voar e nadar ao mesmo tempo, estar em dois lugares simultaneamente, e quem sabe até mesmo ver um quadrado redondo. No inconsciente, diferentes conteúdos, diametralmente opostos e mutuamente exclusivos, podem conviver sem se anularem.

Para Simondon, por sua vez, a contradição lógica presente no princípio do terceiro excluído só se aplica à realidade já individuada. O ser, enquanto pré-individual, correspondendo a uma pluralidade intensiva não resolvida, não possui qualquer contradição lógica, pois esta só pode ser dita a partir da relação de indivíduos relativamente coerentes em si mesmos., como vimos. No pré-individual, a contradição - ou melhor, a diferença ou disparação - é tão somente genética.

A contradição, na psicanálise, só se dará para e no ego. O Isso em si mesmo, por mais que possa apresentar componentes "altamente organizados, livres de autocontradição" (Idem, 1996a p. 193) - como no caso de uma memória -, o faz apenas através das “aquisições do sistema Cs¹."(Idem). O ego se desenvolve topograficamente a partir do mecanismo dinâmico do sistema Perceptivo-Consciente. A consciência nada mais é do "que a superfície do aparelho mental, ou seja, função de um sistema que, espacialmente é o primeiro a ser atingido a partir o mundo externo.” (Idem, 1996c p. 33) Ela figura como o núcleo atual do ego, estando contido nele na forma da percepção imediata, tanto do mundo exterior quanto interior. Por esta razão, o ego é primeiramente perceptivo. A percepção, como demonstra Simondon, é uma forma de individuação. Através dela “o indivíduo se individua na medida que percebe seres, constituindo uma individuação através da ação ou da construção fabricadora, e forma parte do sistema que compreende sua realidade junto dos objetos que percebe ou que constitui." (Simondon, op. cit, p. 366) A percepção é uma atividade constitutiva, individuante, pelo qual o indivíduo se produz ao produzir um meio, ao construir objetos para sua orientação. Para Freud, será este procedimento que instaurará a emergência do ego, na medida em que ele nada mais é do que uma "parte especialmente diferenciada do Isso a partir da influência do meio externo." (Freud, op. cit., Idem, 1996c,

1 Querendo isso indicar consciência. 
p. 12) ${ }^{2}$. Assim, a contradição só existirá para o ego na medida em que ele próprio já é indivíduo, construído a partir da percepção, sendo esta, uma atividade constitutiva e individuante em relação as impressões do meio exterior. Deste modo, podemos ver como a ausência de contradição no isso se vê próxima ao a mesma ausência no pré-individual de Simondon.

O processo primário no isso remete às vicissitudes da dinâmica pulsional segundo graus variados de catexia: "no Ics. só existem conteúdos, catexizados com maior ou menor força.” (Idem, 1996b, p. 135). A mobilidade pulsional pode ser interpretada como uma relação diferencial e intensiva entre diversos instintos, que podem se agrupar - pela condensação - ou se deslocar, em uma miríade de relações possíveis aos quais correspondem - pela intensidade de catexia - a posição funcional de determinado conteúdo ideacional no ego, no pré-consciente ou no reprimido. Com efeito, a repressão, que constitui em parte significativa o ego, se dá através de anticatexias pelas quais se procura deslocar determinado conteúdo através de uma realocação do investimento pulsional correspondente. O aspecto relevante aqui é que a individuação de determinado conteúdo mental em sua participação em um ou mais sistemas depende das relações intensivas de cunho pulsional no inconsciente. Como o pré-individual de Simondon, o Isso de Freud é pura relação de forças, pura diferença em uma regime intensivo.

A intemporalidade corresponde ao fato de que os conteúdos inconscientes “em, primeiro lugar, que não são ordenados temporalmente, que o tempo de modo algum os altera e que a ideia de tempo não lhes pode ser aplicada." (Idem, 1996d, p. 38) A referência ao tempo vincula-se ao trabalho do sistema Cs (consciência), sobretudo, pela percepção: “nossa ideia abstrata de tempo parece ser totalmente derivada do método de funcionamento do sistema Pcpt-Cs. (percepção - consciência)" correspondendo a "uma percepção de sua própria parte neste método de funcionamento, o qual pode corresponder a uma outra maneira de fornecer um escudo contra estímulos.” (Idem) Na individuação de Simondon, a temporalidade também só existe a partir do processo mesmo de individuação, estando ausente no pré-individual. O passado e o futuro

2 Apesar do ego ter seu núcleo na percepção e consciência, ele é mais vasto que isso, tendo em si conteúdos inconscientes. Ele não é apenas percepção e consciência por mais que estas estejam em seu núcleo. 
são derivados do processo de individuação e não são anteriores a ele. Dar a ontogênese a ela mesma, como pretende toda a sua obra, deve necessariamente envolver o tempo no seu modo genético e constituinte. A individuação enquanto devir do ser é presentificação. Na medida em que o presente se presentifica temos um prolongamento da individuação que operará concomitante a uma polarização em passado e futuro; o presente não se dá de uma única vez, mas se prolonga estabelecendo neste prolongamento tanto o passado quanto o porvir. Ora, o ego enquanto indivíduo, produzido pela percepção, é aquele que vivencia o tempo, através do qual este devém passado ou futuro. Enquanto consciência e percepção, ele instaura um presente que estará ausente no Isso. Do mesmo modo que no pré-individual, este não possui temporalidade, sendo esta consequência apenas da individuação enquanto processo.

Por fim, a "substituição da realidade externa pela psíquica” nos apresenta de imediato um problema. Parece-nos que a postulação leva à derivação de uma disjunção entre realidade externa e interna, sem levar em consideração o ponto em que se forma a exterioridade e a interioridade, no caso, o ego em sua função membranosa. O termo substituição indica a existência de duas realidades distintas, independentes, que podem ser cambiadas uma pela outra. O isso, sendo pré-individual, não comporta ainda esta disjunção, e sendo mais amplo que o eu nele inserido, surge a dúvida: como podemos falar de um indivíduo através do qual haveria uma realidade externa e uma realidade psíquica interna? Este problema, de fato, levanta outra questão ainda mais complexa no pensamento freudiano: o inconsciente é individual ou coletivo? Se o individuo corresponde ao eu, este enquanto parte do isso, não pode possuir um isso pessoal, individual, pela simples razão de que ele que está no isso e não o contrário. Seria necessariamente coletivo, por consequência. Mesmo que Jung (2002, p. 15) afirme que Freud tenha abandonado uma concepção individual do inconsciente a partir justamente do conceito de isso e de supereu e Lacan afirme que o inconsciente é transindividual (Lacan, 2014, p. 123), a nossa impressão particular é que é possível depreender tanto uma interpretação quanto a outra. No entanto, aos nossos propósitos aqui, uma interpretação do inconsciente freudiano que o tome como individual e não coletivo nos imporia grandes limitações teóricas. Optaremos, então, pela interpretação oposta, tomando-o como não-individual.

Deste modo, esperamos ter demonstrado como o isso é pré-individual na medida em que consiste de catexias, diferenças intensivas entre pulsões, que se defasam em es- 
truturas atuais na forma do ego. A intemporalidade e a ausência de contradição lógica sustentam tal aproximação. Não há tempo senão para a consciência e a percepção do indivíduo relativamente constituído; nem contradição possível em uma relação cujos termos ainda não foram individuados. Igualmente, o isso não é individual, não é propriedade do indivíduo, mas é mais vasto e ontologicamente anterior a ele, tal como o pré-individual em relação ao ente individuado.

\section{O SUJEITO É O ISSO}

Esperamos, assim ter demonstrado que o isso, enquanto anterior ao ego, não pode, justamente por isso, ser individual; é coletivo, transdutivo. O indivíduo é uma resolução dos seus potenciais disponíveis, a solução entre o vetor centrípeto da pulsão e a resistência do meio exterior; enquanto tal, ele mesmo é uma operação transdutiva. Por fim, caráter pré-individual do isso, deve ser frisado em sua relatividade; em sentido restrito indica certo grau de individuação que ainda comporta potenciais de variação, uma permanência de metaestabilidade, o que corresponderia ao ego; em sentido geral, remete a natureza inteira e ao próprio devir do ser. Se nos aprofundarmos no isso deixaremos para trás os traços do eu, mesmo o pré-consciente, o reprimido, em direção a própria natureza enquanto pré-individual. Por outro lado, conforme nos aproximamos da sua superfície em direção à consciência, à mobilidade e à percepção, teremos um grau mais e mais coerente de individuação, seja primeiramente pela figura do ego com a sua memória e seus conteúdos latentes, até, por fim, a percepção e consciência atual. Tudo se passa como em um cone, no qual a consciência atual é a ponta e, a natureza, a base.

A título de conclusão, gostaríamos de trazer uma distinção conceitual relevante definida por Simondon: a diferença entre sujeito e indivíduo. O indivíduo distingue-se do sujeito como o eu do isso. Ele é a parte individuada de qualquer ser, que, no entanto, o expressa apenas parcialmente. Para ele, o termo indivíduo no sentido comum seria "dado abusivamente a uma realidade mais completa, a do sujeito completo, que comporta nele, além da realidade individuada, um aspecto não individuado, pré-individual, ou ainda natural." (Simondon, op.cit, p.380) O sujeito é o par pré-individual e indivíduo. Deste modo, o sujeito verdadeiramente completo, para Simondon, é “a unidade condensada e sistematizada das três fases do ser." (Idem) Pelo que expomos até aqui, podemos ver como esta unidade só pode ser a do isso; é ele, que como pré- 
-individual e assim, no sentido geral, o próprio ser, se defasa em relação a si mesmo, se diferenciando em indivíduo. Deste modo, podemos afirmar, com base em tudo que foi exposto, que o verdadeiro sujeito não é a consciência, nem mesmo o ego: o único e verdadeiro sujeito é o isso.

\section{BIBLIOGRAFIA}

CHATEAU, J. “Préface sur Communication et Information”. In : SIMODON, Gilbert. Communication et Information: cours et conferences. Paris: Presses Universitaires de France, 2015. FREUD. S. “A história do movimento psicanalítico, Artigos sobre a Metapsicologia e outros trabalhos". In: Edição Standard Brasileira das Obras Completas de Sigmund Freud, V. XIV. Trad. Jaime Salomão. Rio de Janeiro: Imago, 1996A.

. “Novas conferências introdutórias sobre a psicanálise e outros trabalhos”. In: Edição Standard Brasileira das Obras Completas de Sigmund Freud, V. XXII. Trad. Jaime Salomão. Rio de Janeiro: Imago, 1996B.

. “O Ego e o Id e outros trabalhos”. In: Edição Standard Brasileira das Obras Completas de Sigmund Freud, V.XIX. Trad. Jaime Salomão. Rio de Janeiro: Imago. 1996C.

“Além do Princípio do Prazer, Psicologia de Grupo e outros trabalhos”. In: Edição Standard Brasileira das Obras Completas de Sigmund Freud, V.XVIII. Trad. Jaime Salomão. Rio de Janeiro: Imago, 1996D.

JUNG, C. Os arquétipos e o inconsciente coletivo. Trad. Maria Luíza Appy, Dora Mariana R. Ferreira da Silva. Petrópolis: Editora Vozes, 2002.

LACAN, J. Escritos. Trad. Inês Oseki-Depré. São Paulo: 2014.

SIMONDON, G. La individuación a la luz de las nociones de forma y información. Trad. Pablo Esteban Rodriguéz. Cactus. Buenos Aires, 2009. 